\title{
Role of Alcohol P-450-Oxygenase (APO) in Microsomal Ethanol Oxidation ${ }^{1}$
}

\author{
DENNIS R. KOOP AND MINOR J. COON ${ }^{2}$
}

Department of Biological Chemistry, Medical School, The University of Michigan, Ann Arbor, MI 48109-0010

\begin{abstract}
KOOP, D. R. AND M. J. COON. Role of alcohol P-450-oxygenase (APO) in microsomal ethanol oxidation. ALCOHOL 2(1) 23-26, 1985. - The form of liver microsomal cytochrome P-450 induced by chronic administration of ethanol to rabbits, designated as $\mathrm{P}-450 \mathrm{ALC}$ or $\mathrm{P}-450$ isozyme $3 \mathrm{a}$, has been purified to homogeneity as judged by several criteria, including $\mathrm{NH}_{2}$ - and $\mathrm{COOH}$-terminal amino acid sequence determination. The reconstituted alcohol-P-450 oxygenase (APO) system containing P-450ALC and NADPH-cytochrome P-450 reductase catalyzes the oxidation of a variety of primary and secondary alcohols to aldehydes and ketones, including methanol, ethanol, $n$-propanol, $n$-butanol, 2-butanol, $n$-pentanol, and cyclohexanol. Other purified P-450 cytochromes, including isozymes $2,3 \mathrm{~b}, 3 \mathrm{c}, 4$, and 6 , are much less active than $\mathrm{P}-450 \mathrm{ALC}$ in the oxidation of alcohols. That P-450ALC functions in ethanol oxidation in liver microsomal membranes as well as in the reconstituted system was shown by immunochemical experiments involving inhibition by sheep anti-P-450ALC antibodies. We conciude that P-450ALC is the predominant ethanol-oxidizing cytochrome present after induction by chronic alcohol administration and that the other P-450 cytochromes have low but significant activity in both control and ethanolinduced animals.
\end{abstract}

$\begin{array}{lll}\text { P-450Alc P-450 isozyme 3a } & \begin{array}{l}\text { Cytochrome P-450, role in ethanol oxidation } \\ \text { Microsomal ethanol oxidation }\end{array} & \text { Antibodies to P-450ALC } \\ \text { Alcohol P-450-oxygenase (APO) } & \text { M }\end{array}$

FOLLOWING the solubilization and reconstitution of the hepatic microsomal cytochrome P-450 enzyme system from fractions containing the cytochrome, NADPH-cytochrome $\mathrm{P}-450$ reductase, and phosphatidylcholine $[14,15]$, this laboratory turned its attention to the question of whether the many known activities are due to one or more forms of the cytochrome. The separation and purification of multiple forms of cytochrome P-450 several years later permitted their characterization as isozymes having distinct chemical, physical, and catalytic properties [9], and it is now widely accepted that the hepatic P-450 family consists of members having somewhat different but overlapping substrate specificities. The multiplicity of P-450's has been reviewed elsewhere $[4,5,16]$. Although it would be highly desirable to name the individual oxygenases on the basis of function (that is, according to the substrate preferentially attacked) the overlap is such that various laboratories have resorted to designating the liver microsomal $\mathrm{P}-450$ isozymes by relative electrophoretic mobility, inducers used, chronological order of discovery, spin state, or other arbitrary methods. On the other hand, many of the P-450's in endocrine tissues appear to be quite specific in the site of hydroxylation of a particular steroid and are named accordingly. such as $\mathrm{P}-450_{11 \beta}$ for the steroid $11 \beta$-hydroxylase [5].

This laboratory has purified and characterized a unique isozyme of P-450 from liver microsomes of ethanol-treated rabbits $[6,10,19]$. This cytochrome was designated as $P-450$ isozyme $3 a$ on the basis of its electrophoretic mobility relative to that of the previously isolated cytochromes, but we also refer to it functionally as P-450ALC because of its activ- ity toward ethanol and other alcohols. The possible role of cytochrome P-450 in alcohol oxidation has been the subject of much debate, as reviewed previously $[7,10,19,28]$, and no attempt will be made here to recount earlier contributions in detail. Mention should be made, however, of the contribution of Lieber and colleagues, who attributed the enhanced alcohol metabolism in microsomes from alcoholtreated rats to a hepatic microsomal ethanol-oxidizing system distinct from the known systems involving alcohol dehydrogenase and catalase [13] and reported an increase in two proteins following ethanol treatment and solubilized and reconstituted the microsomal ethanol-oxidizing activity [21]. Clearly, the isolation and characterization of a purified enzyme that is enhanced by ethanol treatment of the animals and has significant ethanol-metabolizing activity [10] were essential to a biochemical understanding of the microsomal system.

The present paper is concerned with the catalytic properties of P-450ALC in comparison to those of the other known hepatic cytochromes and with immunochemical evidence that this P-450 isozyme plays a role in ethanol oxidation in liver microsomal membranes. On the basis of the known involvement of the P-450 oxygenases in the oxidation of ethanol and other alcohols to the corresponding aldehydes and ketones, recommendations on terminology are made.

\section{RESULTS AND DISCUSSION}

Activity of Various Alcohols With Ethanol-Induced P-450

The rates of oxidation of several alcohols by P-450ALC are

'This research was supported by Grant AA-06221 from the National Institute on Alcohol Abuse and Alcoholism.

${ }^{2}$ Requests for reprints should be addressed to M. J. Coon. 
TABLE 1

SUBSTRATE SPECIFICITY OF PURIFIED CYTOCHROME P-450ALC

\begin{tabular}{lcc}
\hline Substrate & $\begin{array}{c}\text { Substrate } \\
\text { concentration }\end{array}$ & $\begin{array}{c}\text { Turnover number } \\
\text { (nmol product formed/ } \\
\text { min/nmol/P-450) }\end{array}$ \\
\hline Ethanol & $(100 \mathrm{mM})$ & 7.7 \\
$n$-Butanol & $(30 \mathrm{mM})$ & 12.0 \\
2-Butanol & $(30 \mathrm{mM})$ & 11.9 \\
$n$-Pentanol & $(10 \mathrm{mM})$ & 13.0 \\
Cyclohexanol & $(10 \mathrm{mM})$ & 7.6
\end{tabular}

The values presented were determined in a reconstituted system containing $0.1 \mu \mathrm{M}$ P-450, $0.3 \mu \mathrm{M}$ NADPH-cytochrome P-450 reductase, $30 \mu \mathrm{g} / \mathrm{ml}$ dilauroylglyceryl-3-phosphorylcholine, $0.05 \mathrm{M}$ potassium phosphate buffer, $\mathrm{pH} 7.6$, and $1.0 \mathrm{mM}$ NADPH as the last addition in a final volume of $1.0 \mathrm{ml}$. The temperature was $30^{\circ} \mathrm{C}$. Substrates were at the concentration indicated in the table; all were at enzyme-saturating levels except cyclohexanol, which was at about the $\mathrm{K}_{\mathrm{M}}$ level; higher concentrations of cyclohexanol appeared to exceed solubility. Acetaldehyde, butyraldehyde, and valeraldehyde were determined by gas chromatography of the headspace gas of the reaction mixtures; for cyclohexanone determination, a dichloromethane extract of the reaction mixture was dried and concentrated before analysis by gas chromatography.

shown in Table 1. Both primary and secondary alcohols are attacked, to give aldehydes and ketones, respectively, and it is obvious from the data given that higher molecular weight alcohols are as good as or in some instances better substrates than ethanol. In the experiments shown the reductase by itself had very low but significant activity. In studies in which the reductase had low but significant activity due to the presence of traces of iron, we reported than methanol is a relatively poor substrate and that $n$-propanol is superior to ethanol [19]. Since catalase has little activity toward propanol or butanol [3], it is evident that our purified P-450 preparation was not contaminated by catalase. Furthermore. since oxidized pyridine nucleotides do not support alcohol oxidation by $\mathrm{P}-450$, alcohol dehydrogenase activity can also be excluded. P-450ALC had only very weak activity toward drugs that were tested but had a turnover number for aniline $p$-hydroxylation comparable to the value for ethanol oxidation. Since ethanol administration to animals is known to enhance the aniline hydroxylase activity of rat [24] and rabbit microsomal suspensions [19], the high activity of P-450ALC toward this aromatic amine was not unexpected.

\section{Comparison of P-450 Isozymes in Alcohol Oxidation}

The activities of the various P-450 isozymes from rabbit liver microsomes in ethanol oxidation are shown in Table 2. P-450ALC is clearly the most effective, but it should be noted that the other five isozymes have weak but significant activity. Under the conditions used the reductase alone had only trace activity, presumably via a hydroxyl radical pathway $[19,29,30]$.

\section{Immunochemical Evidence for Role of P-450 in Ethanol Oxidation in Liver Microsomal Membranes}

We have recently made use of antibody to P-450ALC produced by immunization of yearling female sheep to de-
TABLE 2

CATALYTIC ACTIVITY OF SIX PURIFIED P-450 ISOZYMES AND NADPH-CYTOCHROME P-450 REDUCTASE IN ETHANOL OXIDATION

\begin{tabular}{lc}
$\begin{array}{c}\text { Enzyme } \\
\text { assayed }\end{array}$ & $\begin{array}{c}\text { Turnover number } \\
\text { (nmol acetaldehyde formed/ } \\
\text { min/nmol enzyme) }\end{array}$ \\
\hline P-450 2 & 0.85 \\
P-450 3a (P-450ALC) & 7.72 \\
P-450 3b & 0.48 \\
P-450 3c & 0.58 \\
P-450 4 & 1.14 \\
P-450 6 & 2.41 \\
Reductase & 0.17 \\
\hline
\end{tabular}

The reaction mixtures were as in Table 1 , except that P-450 was omitted when the activity of the reductase in ethanol oxidation was assayed.

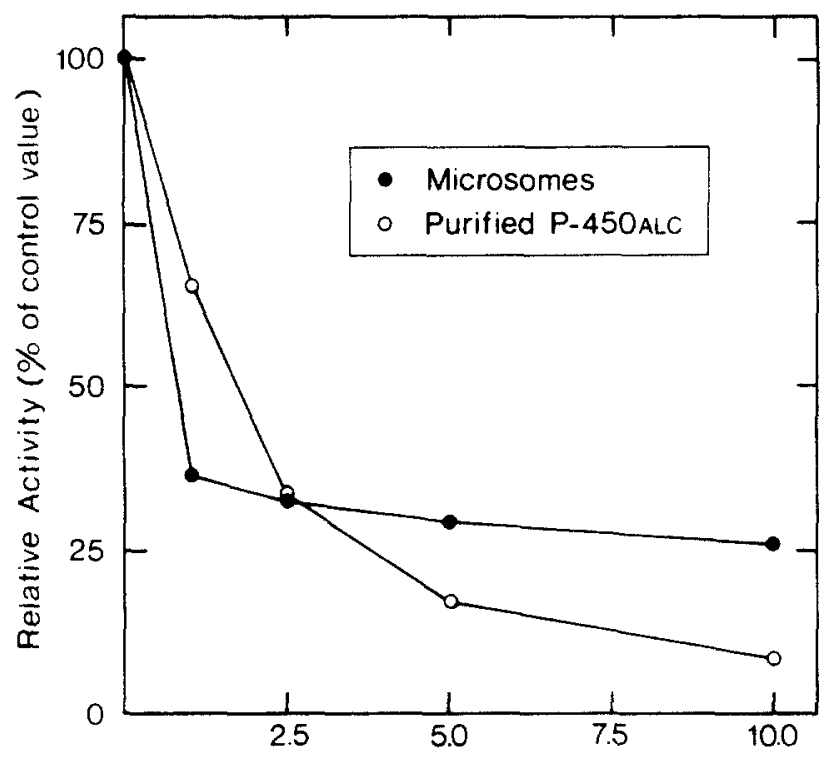

Anti-3a IgG Added ( $\mathrm{mg}$ protein per nmol P-450)

FIG. 1. Inhibition of ethanol oxidation in microsomes and in the reconstituted system containing P-450ALC as a function of amount of anti-P-450ALC IgG added. The conditions for the reconstituted system were as in Table 1. For the microsomal system, rabbit liver microsomes from ethanol-induced animals $(0.27 \mathrm{mg}$ of protein) and $1.0 \mathrm{mM} \mathrm{NaN}_{3}$ were present, purified reductase and P-450ALC and phosphatidylcholine were omitted, and the level of preimmune sheep IgG was adjusted so that with varying anti-P-450ALC IgG the total IgG concentration remained constant $(10 \mathrm{mg}$ of $\mathrm{IgG}$ protein/nmol P-450).

termine the role of this enzyme in alcohol oxidation in hepatic microsomes from ethanol-treated and untreated rabbits [11]. As shown in Fig. 1, the addition of anti-P-450 resulted in greater than $90 \%$ inhibition of alcohol oxidation by this purified isozyme in the reconstituted system and up to $75 \%$ inhibition of the activity of microsomes from the ethanol- 
treated animals. In experiments not presented here, the inhibition of the acitivity of microsomes from control animals was only about one half as great. The residual activity seen in the figure at maximal concentrations of the antibody most likely represents the sum of the activities of P-450 isozymes other than P-450ALC present in the microsomal preparation. Thus, the results indicate that the enhanced monooxygenase activity of liver microsomes as a result of ethanol treatment represents catalysis by the induced cytochrome, P-450ALC.

\section{Role of P-450ALC in Toxicity of Foreign Compounds After Ethanol Administration}

Ethanol-drug interactions are known to be complex $[12,18]$, and ethanol administration to animals or man is recognized as possibly affecting the normal metabolism or the toxicity or teratogenicity of other foreign compounds [23]. Some such changes involve the P-450 system, but much remains to be learned as to which isozymes are involved as to whether induction of P-450ALC is primarily responsible. Some well known examples of the effects of chronic ethanol consumption are: increased hepatotoxicity of carbon tetrachloride [8,27], acetaminophen [17,25], and cocaine [26], and increased metabolism of methadone in rats [2], hematotoxicity of inhaled benzene in peripheral blood, bone marrow, and spleen cells in mice [1], and variable effects on drug metabolism and toxicity in human alcoholics [22]. We have recently compared the activities of our isolated P-450 isozymes in acetaminophen activation as measured by formation of the glutathione conjugate [20]. Isozyme 4 was most active, followed by $3 \mathrm{a}$ and 6 , while isozymes $3 \mathrm{~b}$ and $3 \mathrm{c}$ were much less effective and 2 produced only trace amounts of the conjugate that were too small to be determined accurately. It should be noted that, after alcohol treatment of the rabbits. the three main P-450 cytochromes present in microsomes are the one that could contribute most strongly to the hepatotoxicity of this drug.

\section{Terminology}

As already indicated. the overlapping substrate specificity of many of the mammalian P-4.50 cytochromes has made a system of nomenclature based on substrate specificity generally unsuitable. Almost all laboratories working with rabbit liver microsomal P-450 have agreed to use the numbering system based on relative electrophoretic behavior [9] and to exchange purified cytochrome preparations when doubt exists about the possible identity of enzymes having similar electrophoretic behavior but known to be induced by different agents and to catalyze oxygenation of any of a series of substrates depending upon a particular investigator's interest in drugs, carcinogens, anesthetics, or whatever. Characterization by peptide mapping and $\mathrm{NH}_{2}$ - and $\mathrm{COOH}$-terminal amino acid sequencing has proved particularly helpful in establishing identity or nonidentity [4]. Thus, the P-450 cytochrome induced by ethanol and exhibiting high activity in ethanol oxidation was designated as isozyme 3a by its electrophoretic behavior and is readily compared with cytochrome preparations obtained with other inducers by peptide mapping and by its known amino acid sequence [10]: $\mathrm{NH}_{2}-$ Ala-Val-Leu-Gly-Ile-Thr-Val-Ala-Leu-Leu . . . Val-ProLeu-COOH. In view of the desirability of indicating function where possible, we have also designated $\mathrm{P}-450 \mathrm{3a}$ as P-450ALC to indicate its role in the oxidation of alcohols, particularly ethanol. Since the other rabbit liver microsomal P-450's have much weaker activity toward alcohols and relatively high activity toward other substrates, they will continue to be designated by the numbering system or, where appropriate, by subscripts to indicate their preferred substrates.

The alcohol-oxidizing enzyme system under discussion is designated as APO for "alcohol P-450-oxygenase," a term that suitably indicates the nature of the oxygenating catalyst and is comparable to ADH for alcohol dehydrogenase. The term APO has the advantages of indicating that alcohols in general are substrates, not just ethanol, that the P-450 family of catalysts is involved, and that the mechanism is one of oxygenation. The term MEOS for "microsomal ethanol oxidizing system" proved useful in the early days of investigation of this pathway but has the drawbacks of emphasizing microsomes (whereas P-450 also occurs in mitochondria and nuclei), of designating ethanol (whereas the system has much broader substrate specificity), and, of greatest concern, of referring to an unidentified oxidizing system. Designation by a term that specifies "P-450" immediately brings to mind the chemical and physical properties of this unique family of hemeproteins as well as its role in the metabolism of an almost unlimited number of lipids and other xenobiotics as well.

\section{REFERENCES}

1. Baarson, K. A., C. A. Synder. J D Green. A. Sellakumar. B. D. Goldstein and R. E. Alherr. The hematotoxic effect of inhaled benzene on peripheral hloud. hone marrou, and spleen

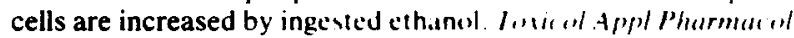
64: 393-404, 1982.

2. Borowsky, S. A. and C. S. Licher Interaction of methadone

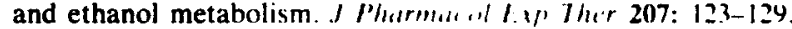
1978.

3. Chance, B. and N. Oshino. Kinetles and mechanism of catalase in peroxisomes of the mitochondrial fraction. Bischem I 122: 225-233, 1971.

4. Coon, M. J., S. D. Black. D. R. Koop. E. T. Morgan and G. E. Tarr. Structural and catalytic studies with purified microsomal enzymes. In: Microsomes. Drus O Widutums, and Drug Toxicity, edited by $R$. Sato and $R$. Kato. Tokyo: Japan Scientific Societies Press, 1982, pp. 13-23.

5. Coon, M. J. and D. R. Koop. P-450 oxygenases in lipid transformation. In: The Enzyme's. vol 16. edited by P. D. Boyer. New York: Academic Press, 1983, pp. 645-677.
6. Coon, M. J., D. R. Koop and E. T. Morgan. Alcohol oxidation by isozyme 3a of liver microsomal cytochrome P-450. Pharmacol Bischem Bchav 18: Suppl 1, 177-180, 1983.

7. Coon, M. J., A. V. Persson and J. S. French. On the possible relationship of cytochrome P-450 to alcohol metabolism: Fundamental aspects of the microsomal hydroxylation system, including properties and interactions of the components. In: Alcohol and Aldehyde Metabolizing Systems-IV. Adv. Exp. Med. Biol., vol 132, edited by R. G. Thurman. New York: Plenum Press, 1980, pp. 11-22.

8. Hasumura, Y., R. Teschke and C. S. Lieber. Increased carbon tetrachloride hepatotoxicity, and its mechanism, after chronic ethanol consumption. Gastroenterology 66: 415-422, 1974.

9. Haugen, D. A., T. A. van der Hoeven and M. J. Coon. Purified liver microsomal cytochrome P-450. Separation and characterization of multiple forms. $J$ Biol Chem 250: 3567-3570, 1975. 
10. Koop, D. R., E. T. Morgan, G. E. Tarr and M. J. Coon. Purification and characterization of a unique isozyme of cytochrome P-450 from liver microsomes of ethanol-treated rabbits. $J$ Biol Chem 257: 8472-8480, 1982.

11. Koop, D. R., G. D. Nordblom and M. J. Coon. Role of cytochrome P-450 in liver microsomal ethanol oxidation: immunochemical evidence. Arch Biochem Biophys 235: 228-238. 1984.

12. Lieber, C. S. Interaction of ethanol with drug toxicity. Am J Gastroenterol 74: 313-320, 1980.

13. Lieber, C. S. and L. M. DeCarli. Hepatic microsomal ethanoloxidizing system. In vitro characteristics and adaptive properties in vivo. I Biol Chem 245: 2505-2512, 1970.

14. Lu, A. Y. H. and M. J. Coon. Role of hemoprotein P-450 in fatty acid $\omega$-hydroxylation in a soluble enzyme system from liver microsomes. $J$ Biol Chem 243: 1331-1332, 1968.

15. Lu, A. Y. H., K. W. Junk and M. J. Coon. Resolution of the cytochrome P-450-containing $\omega$-hydroxylation system of liver microsomes into three components. I Biol Chem 244: 3714 $3721,1969$.

16. Lu, A. Y. H. and S. B. West. Multiplicity of mammalian microsomal cytochromes P-450. Pharmacol Rev 31: 277-295, 1980.

17. McClain, C. J., J. P. Kromhout, F. J. Peterson and J. L. Holtzman. Potentiation of acetaminophen hepatotoxicity by alcohol. J Am Med Assoc 244: 251-253, 1980.

18. Mezey, E. Ethanol metabolism and ethanol-drug interactions. Biochem Pharmacol 25: 869-875, 1976.

19. Morgan, E. T., D. R. Koop and M. J. Coon. Catalytic activity of cytochrome $\mathrm{P}-450$ isozyme 3a isolated from liver microsomes of ethanol-treated rabbits. J Biol Chem 257: 13951-13957, 1982.

20. Morgan, E. T., D. R. Koop and M. J. Coon. Comparison of six rabbit liver cytochrome $\mathrm{P}-\mathbf{4 5 0}$ isozymes in formation of a reactive metabolite of acetaminophen. Biochem Biophys Res Commun 112: 8-13, 1983.

21. Ohnishi, K. and C. S. Lieber. Reconstitution of the microsomal ethanol-oxidizing system. Qualitative and quantitative changes of cytochrome P-450 after chronic ethanol consumption. $J$ Biol Chem 252: 7124-7131, 1977.
22. Pelkonen, $O$. and E. Sotaniemi. Drug metabolism in alcoholics. Pharmacol Ther 16: 261-268, 1982.

23. Randall, C. L., W. J. Taylor, B. Tabakoff and D. W. Walker Ethanol as a teratogen. In: Alcohol and Aldehyde Metabolizing Systems, vol 3, edited by R. G. Thurman. J. R. Williamson, H. R. Drott and B. Chance. New York: Academic Press, pp. 659 $670,1977$.

24. Rubin. E., F. Hutterer and C. S. Lieber. Ethanol increases hepatic smooth endoplasmic reticulum and drug metabolizing enzymes. Science 159: 1469-1471, 1968,

25. Sato, C., Y. Matsuda and C. S. Lieber. Increased hepatotoxicity of acetaminophen after chronic ethanol consumption in the rat. Gastroenterology 80: 140-148, 1981.

26. Smith, A. C., R. N. Freeman and R. D. Harbison. Ethanol enhancement of cocaine-induced hepatotoxicity. Bischem Pharmacol 30: 451-453, 1981.

27. Traiger, G. J. and G. L. Plaa. Relationship of alcohol metabolism to the potentiation of $\mathrm{CCl}_{4}$ hepatotoxicity induced by aliphatic alcohols. J Pharmacol Exp Ther 183: 481-488, 1972.

28. Vatsis, K. P. and M. J. Coon. On the question of whether cytochrome P-450 catalyzes ethanol oxidation: Studies with purified forms of the cytochrome from rabbit liver microsomes. In: Alcohol and Aldehyde Metabolizing Systems, vol 2, edited by R. G. Thurman, J. R. Williamson, H. Drott and B. Chance. New York: Academic Press, 1977, pp. 307-322.

29. Winston, G. and A. I. Cederbaum. NADPH-dependent production of oxy radicals by purified components of the rat liver mixed function oxidase system. I. Oxidation of hydroxyl radical scavenging agents. $J$ Biol Chem 258: 1508-1513, 1983.

30. Winston, G. and A. I. Cederbaum. NADPH-dependent production of oxy radicals by purified components of the rat liver mixed function oxidase system. II. Role in microsomal oxidation of ethanol. J Biol Chem 258: 1514-1519, 1983. 